ISSN 1808-3765

\title{
PROPRIEDADES FÍSICAS DE UM LATOSSOLO VERMELHO CULTIVADO NO SISTEMA PLANTIO DIRETO
}

Fernanda de Fátima da Silva; Onã da Silva Freddi; José Frederico Centurion; Ricardo Garcia Aratani; Fabricia Flavia Andrioli; Itamar Andrioli

Departamento de Solos e Adubos, Universidade Estadual Paulista, Faculdade de Ciências Agrárias e Veterináiras, Jaboticabal, São Paulo, ona_freddi@yahoo.com.br

\section{RESUMO}

A pressão exercida pelo tráfego de máquinas necessário ao cultivo das culturas pode levar à compactação do solo com o tempo de uso do sistema plantio direto. O objetivo do trabalho foi avaliar o efeito do tempo de adoção do sistema plantio direto em algumas propriedades físicas, índice S, e matéria orgânica (MO) de um Latossolo Vermelho distrófico de textura argilosa localizado em Jaboticabal, SP. O delineamento experimental foi o inteiramente casualizado com parcelas subdivididas (quatro sistemas de uso e três camadas do solo avaliadas). Os quatros sistemas de uso foram: sistema plantio direto por 2 anos (PD2), plantio direto por 4 anos (PD4), plantio direto por 6 anos (PD6) e uma área de mata nativa $(\mathrm{MN})$. As camadas do solo avaliadas foram: $0-0,10 ; 0,10-0,20$ e $0,20-0,30 \mathrm{~m}$, nas quais foram determinadas a porosidade do solo, o diâmetro médio ponderado, a densidade do solo, índice $\mathrm{S}$, condutividade hidráulica e o teor de matéria orgânica. Os resultados foram submetidos à análise de variância e, quando esta indicou diferença entre médias, utilizou-se o teste de Tukey a $5 \%$ de probabilidade para compará-las. A mata nativa apresentou o maior teor de matéria orgânica, macroporosidade, condutividade e Índice S; já entre os sistemas de plantio direto não houve diferença entre os parâmetros analisados no experimento, demonstrando que o tempo de seis anos de adoção do sistema não foi suficiente para alterar a qualidade física do solo.

UNITERMOS: densidade do solo, porosidade do solo, índice S, condutividade hidráulica, agregados do solo

SILVA, F. F.; FREDDI, O. S.; CENTURION, J. F.; ARATANI, R. G.; ANDRIOLI, F. F.; ANDRIOLI, I. PHYSICAL PROPERTIES OF AN OXISOL UNDER NO-TILLAGE SYSTEM

\section{ABSTRACT}

The pressure caused by agricultural machinery traffic many result in soil compactation in no-tillage system. The aim of this work was to evaluate no-tillage system onset time on some physical properties, index $\mathrm{S}$ and organic matter (OM) of an oxysol located in Jaboticabal, Sao Paulo State, Brazil. The experiment had completely randomized split-splot design .The treatments consisted of four no-tillage systems: no-tillage for 2 years, no-tillage for 4 years, no-tillage for 6 years and one natural wooded area. The evaluated layers were: 0 $0.10 \mathrm{~m}, 0.10-0.20 \mathrm{~m}$ and $0.20-030 \mathrm{~m}$. The following were determined: soil porosity, soil aggregates, bulk density, index $\mathrm{S}$ and organic matter. The results were submitted to variance 
analysis and when there was a difference between averages, Tukey's test was used to compare them. The natural wooded area showed higher organic matter, macroporosity, hydraulic conductivity and Index S. There was no difference between the studied parameters showing that the no-tillage system for six years was not enough to change the soil physical property.

KEY WORDS: bulk density, soil porosity, index S, hydraulic conductivity, soil aggregates.

\section{INTRODUÇÃO}

Uma das principais conseqüências do manejo inadequado do solo é sua compactação que resulta na perda da sustentabilidade e redução da produtividade das culturas (Oliveira et al., 2003), além de ser um fator físico limitante ao crescimento das plantas (Beutler et al., 2003) e responsável por mudanças na distribuição do sistema radicular em profundidade (Beutler et al., 2004). A adoção de sistemas de manejo conservacionistas e a sucessão de culturas com adubos verdes são práticas que visam preservar a qualidade do solo e do ambiente, sem prescindir da obtenção de elevadas produtividades das culturas de interesse econômico (Carvalho et al., 2004). Uma das características do sistema plantio direto é o acúmulo de resíduos culturais na superfície do solo (Escosteguy et al., 2005).

Entretanto, Stone et al. (2002) relataram em várias situações a ocorrência do aumento da densidade do solo e diminuição da macroporosidade em sistema plantio direto, o que tem sido diagnosticado como compactação, fazendo com que o agricultor seja obrigado a revolver o solo, concordando com Cruz et al. (2003), que avaliando as propriedades físicas e o carbono orgânico (C) de um solo submetido ao sistema plantio direto com três anos de condução e ao sistema de preparo convencional, (uma aração e gradagem), observaram que o solo, sob o preparo convencional apresentava maior porosidade total e macroporosidade na camada de 0-0,10 m e maior microporosidade na camada de $0,10-0,20 \mathrm{~m}$; e os maiores valores de densidade do solo foram observados na camada de $0-0,10 \mathrm{~m}$ sob o sistema plantio direto, verificando-se também aumento do teor de carbono orgânico do solo nessa camada, que não influenciou o diâmetro médio ponderado dos agregados.

Segundo Freitas et al. (2000), o papel fundamental da matéria orgânica (MO) justifica o crescente interesse pela identificação de sistemas de uso e manejo que melhorem o estoque orgânico em solos tropicais. Experimentos de longa duração constituem ferramenta valiosa para o estudo da dinâmica da MO no solo. Assim, Lovato et al. (2004) constataram que em dezesseis anos de cultivo, o sistema plantio direto, pela diminuição da taxa de perda de $\mathrm{MO}$, e os sistemas de culturas com leguminosas, pela alta taxa de $\mathrm{C}$ fotossintetizado e de nitrogênio (N) fixado simbioticamente, são boas alternativas para recuperar os estoques de carbono orgânico total e nitrogênio total do solo. D`Andrea et al. (2004) também afirmaram que a pastagem e o sistema plantio direto, desde que com esquema diversificado de rotação de culturas, são promissores para aumentar os estoques de C orgânico no solo. Segundo Tormena et al. (2004), comparando algumas propriedades físicas, os teores e a taxa de estratificação do carbono orgânico de um Latossolo Vermelho eutroférrico submetido por dez anos ao sistema plantio direto com rotação de culturas e o sistema plantio direto com sucessão de culturas, realizando-se escarificação do solo antes da semeadura da cultura de verão, verificaram que os teores de $\mathrm{C}$ do solo são maiores no sistema plantio direto com rotação de culturas até $0,10 \mathrm{~m}$ de profundidade, enquanto que na camada de $0,10-0,40 \mathrm{~m}$, maiores valores de $\mathrm{C}$ do solo foram observados, quando realizou-se a escarificação antes da semeadura da cultura de 
verão. Os resultados evidenciaram que a maior concentração de carbono orgânico do solo no sistema plantio direto pode resultar em condições físicas mais estáveis às culturas.

Este trabalho teve como objetivo avaliar o efeito do tempo de adoção do sistema plantio direto, cultivado com a sucessão milho e soja, em algumas propriedades físicas, índice $\mathrm{S}$, e $\mathrm{MO}$ de um Latossolo Vermelho de textura argilosa, tendo a mata nativa como testemunha.

\section{MATERIAL E MÉTODOS}

O estudo foi realizado em Jaboticabal, SP, na latitude $21^{\circ} 13^{\prime}$ S e longitude $48^{\circ} 16^{\prime} \mathrm{W}$. O clima da região, de acordo com a classificação climática de Köppen, é do tipo Cwa, com verão quente e inverno seco, precipitação média anual de $1.428 \mathrm{~mm}$ e temperatura média de $21^{\circ} \mathrm{C}$. O relevo varia de plano a suave ondulado, com altitude média de $560 \mathrm{~m}$. No local do experimento, o solo foi classificado como Latossolo Vermelho distrófico, típico, textura argilosa, A moderado, caulinítico, hipoférrico (LVd). A composição granulométrica do solo foi determinada em amostras deformadas, na camada de 0-0,30 m, através da dispersão com $\mathrm{NaOH}(0,1$ mol L-1) e agitação lenta durante 16 horas, sendo o conteúdo de argila obtido pelo método da pipeta (Gee \& Bauder, 1986). O Latossolo Vermelho apresentou na camada de 0$0,30 \mathrm{~m}$ valores médios de $475 \mathrm{~g} \mathrm{~kg}^{-1}$ de argila, $100 \mathrm{~g} \mathrm{~kg}^{-1}$ de silte, $210 \mathrm{~g} \mathrm{~kg}^{-1}$ de areia fina e $215 \mathrm{~g} \mathrm{~kg}^{-1}$ de areia grossa. Antes da instalação do experimento, a área vinha sendo utilizada no sistema de preparo convencional com a sucessão anual de milho e soja no verão.

$\mathrm{O}$ delineamento experimental foi $\mathrm{o}$ inteiramente casualizado com parcelas subdivididas (quatro sistemas de uso e três camadas), com oito repetições. Os quatros sistemas de uso foram: sistema plantio direto por 2 anos (PD2), plantio direto por 4 anos (PD4) e plantio direto por 6 anos (PD6) e uma área de mata nativa (MN), empregada como referência por se tratar de um sistema em equilíbrio sem ação antrópica, porém com ação de organismos de solo. As camadas avaliadas foram: 0-0,10; 0,10-0,20 e 0,20-0,30 m. Apenas para a condutividade hidráulica utilizou-se o delineamento inteiramente casualizado com quatro sistemas de uso e oito repetições. Delimitou-se uma área de $60 \mathrm{~m}^{2}$ para cada sistema de uso do solo.

Para determinação das propriedade físicas do solo, foram coletadas amostras indeformadas do solo, utilizando-se cilindros de $53,1610^{-6} \mathrm{~m}^{3}$ no centro de cada camada. Nas áreas de plantio direto, as amostras foram obtidas no centro da entrelinha da cultura da soja, totalizando 24 amostras por sistema de uso do solo. Nas diferentes camadas, também foram retiradas amostras para a análise química, visando à determinação da matéria orgânica do solo, segundo metodologia citada por Raij et al (1987). A matéria orgânica (MO) foi obtida por oxidação em solução $1 \mathrm{~N}$ de bicromato de potássio em meio ácido e titulação de excesso de bicromato em solução de sulfato ferroso amoniacal $0,5 \mathrm{~N}$, usando difenilamina como indicador.

Após devidamente preparadas, as amostras com estrutura não deformada foram saturadas por meio de elevação gradual de uma lâmina de água em uma bandeja e então submetidas às tensões de 0,$001 ; 0,006 ; 0,01 ; 0,033 ; 0,06$ e $0,3 \mathrm{MPa}$, em câmaras de Richards (Klute, 1986). Ao atingir o equilíbrio, foram pesadas e, na seqüência, as amostras foram secadas em estufa a $105^{\circ} \mathrm{C}$ durante 24 horas para determinação do conteúdo de água em cada tensão (Gardner, 1986) e da densidade do solo (Blake \& Hartge, 1986). A microporosidade foi determinada por secagem, na tensão de $0,006 \mathrm{MPa}$, a porosidade total segundo Danielson 
\& Sutherland (1986), e a macroporosidade obtida por diferença entre a porosidade total e a microporosidade.

As curvas de retenção de água foram ajustadas pelo modelo proposto por Genuchten (1980), a partir do qual foi obtido a inclinação da curva no ponto de inflexão, e, conseqüentemente, o índice $\mathrm{S}$, como segue:

$$
S=-n\left(\theta_{\text {sat }}-\theta_{\text {res }}\right)\left[1+\frac{1}{m}\right]^{-(1+m)}
$$

onde: $\mathrm{n}$ e m são parâmetros que governam o formato da curva; $\theta_{\text {sat }}$ e $\theta_{\text {res }}$ são a umidade na saturação e residual, respectivamente.

Para determinação da agregação do solo, foi retirada uma amostra por camada em todas as parcelas, que foram secas ao ar e peneiradas em malha de 7,93 $\mathrm{mm}$, e após analisadas por peneiramento a úmido, seguindo o método proposto por Yooder (1936). O diâmetro médio ponderado dos agregados estáveis em água (DMP) foi calculado pelo método descrito por Kiehl (1979) da seguinte maneira:

$$
D M P=\sum_{i=1}^{n}(x i . w i)
$$

onde: wi é igual a proporção de cada classe em relação ao total; e xi é igual ao diâmetro médio das classes $(\mathrm{mm})$.

Para determinação da permeabilidade do solo, foi utilizado o permeâmetro (2800 KI Guelph Permeameter) instalado a $0,15 \mathrm{~m}$ de profundidade e submetido a duas cargas hidráulicas $(0,03$ e $0,06 \mathrm{~m}$ de coluna de água), sendo as leituras realizadas através do nível da coluna de água presente no aparelho e, a partir do momento da estabilização das leituras, utilizou-se a média das três últimas e calculou-se a condutividade hidráulica saturada $\left(\mathrm{C}_{\mathrm{hs}}\right)$ de acordo com a seguinte expressão:

$$
\left.\mathrm{C}_{\mathrm{hs}}=\left\{\left[(0,0041)(32,39)\left(\mathrm{x}_{1}\right)\right]\right\}-\left[(0,0054)(35,39)\left(\mathrm{x}_{2}\right)\right]\right\} \mathrm{fc}
$$

onde: $\mathrm{x}_{1}$ representou a média das três últimas leituras com carga hidráulica de $0,06 \mathrm{~m}$ de coluna de água, em $\mathrm{cm} \mathrm{s}^{-1} ; \mathrm{x}_{2}$ representou a média das três últimas leituras com carga hidráulica de $0,03 \mathrm{~m}$ de coluna de água, $\mathrm{em} \mathrm{cm} \mathrm{s}^{-1}$; e fc representou o fator de conversão para $\mathrm{mm} \mathrm{h}^{-1}, 36000$.

Os resultados foram submetidos à análise de variância e quando esta indicou diferença, entre médias, utilizado-se o teste de Tukey a 5\% de probabilidade.

\section{RESULTADOS E DISCUSSÃO}

Pode-se observar pela Tabela 1, que o teor de MO em todas as camadas da mata nativa foi superior à média das camadas dos demais tratamentos, provavelmente pelo grande aporte de resíduos orgânicos e o não revolvimento do solo, conforme resultados obtidos por 
Albuquerque et al. (2005). Segundo Tognon et al. (1998), as diferenças nos teores de MO entre a mata nativa e os demais tratamentos podem estar relacionadas à própria ação da vegetação, a sua natureza e ao tipo de sistema radicular. No caso da mata nativa, D'andrea et al. (2004) verificaram que houve acentuado acúmulo de MO na superfície do solo devido à reciclagem dos elementos constituintes dos galhos, folhas e sistema radicular superficial. Nos sistemas de preparo convencionais, existem condições que facilitam a decomposição da MO do solo, em decorrência do revolvimento, incorporação e do aumento da aeração do solo. Observa-se, também, que em nenhum tratamento houve variação no teor de $\mathrm{MO} \mathrm{em}$ profundidade; e que seis anos de adoção do sistema de plantio direto não foram suficientes para alterar o teor de MO do solo sob sistema plantio direto, constituindo-se num dos principais problemas para a adoção deste sistema na região.

Tabela 1. Teor de matéria orgânica de um Latossolo Vermelho submetido a diferentes sistemas de uso e manejo.

\begin{tabular}{|c|c|c|c|c|}
\hline \multirow{2}{*}{$\begin{array}{c}\text { Camada } \\
\text { (m) }\end{array}$} & \multicolumn{4}{|c|}{ Sistemas de uso e manejo } \\
\hline & PD2 & PD4 & PD6 & $\mathrm{MN}$ \\
\hline & -------------. & -------- & & --- \\
\hline $0-0,10$ & $15 \mathrm{Ba}$ & $17 \mathrm{Ba}$ & $19 \mathrm{Ba}$ & $53 \mathrm{Aa}$ \\
\hline $0,10-0,20$ & $15 \mathrm{Ba}$ & $19 \mathrm{Ba}$ & $19 \mathrm{Ba}$ & $53 \mathrm{Aa}$ \\
\hline $0,20-0,30$ & $15 \mathrm{Ba}$ & $18 \mathrm{Ba}$ & $18 \mathrm{Ba}$ & $47 \mathrm{Aa}$ \\
\hline
\end{tabular}

MN: mata nativa; PD2: plantio direto com 2 anos de condução; PD4: plantio direto com 4 anos de condução; PD6: plantio direto com 6 anos de condução. Médias seguidas da mesma letra na coluna não diferem estatisticamente pelo teste de Tukey a 5\%. Letras maiúsculas referem-se à comparação de tratamentos numa mesma camada e as minúsculas comparam médias de camadas de um mesmo tratamento. (CV =18,99\%)

O PD6 apresentou a maior microporosidade e o PD2 a menor sendo que o PD4 não apresentou diferença tanto para o PD2 como para o MN (Tabela 2). A maior microporosidade encontrada no PD6, provavelmente, seja devida ao maior tempo de adoção do sistema plantio direto e, conseqüentemente, ao maior tráfego de máquinas sobre o solo. $\mathrm{O}$ volume de microporos aumentou com a profundidade em todos os tratamentos, possivelmente pelo aumento da densidade do solo, diminuição da macroporosidade, concordando com Klein \& Libardi (2002).

A MN apresentou a maior macroporosidade quando comparada aos demais tratamentos devido à ausência do tráfego de máquinas e o maior teor de $\mathrm{MO}$ do solo. $\mathrm{Na} \mathrm{MN}$, os valores de macroporos e porosidade total reduziram com o aumento da profundidade. Segundo Spera et al. (2004), esse maior valor para porosidade total na camada superficial reflete menor densidade do solo.

Os demais tratamentos não apresentaram diferença significativa entre as camadas para macroporosidade e porosidade total, com exceção apenas para o PD2 que apresentou maior macroporosidade na camada de $0-0,10 \mathrm{~m}$ em relação apenas à camada de 0,10-0,20 m. Albuquerque et al. (2001) também verificaram maior valor da porosidade total em solo sob floresta subtropical, em comparação aos tratamentos com solos sob ação antrópica. A porosidade total e a macroporosidade decresceram com o aumento da densidade do solo, concordando com os resultados obtidos por Souza et al. (2005). Segundo Stone et al. (2002), a pressão mecânica exercida sobre os agregados pela compactação deve ter provocado a sua ruptura, facilitando a aproximação das partículas, cuja conseqüência imediata foi a redução da 
porosidade total pela diminuição dos poros maiores e com aumento no número de poros menores, fato também observado por Klein \& Libardi (2002).

Tabela 2. Propriedades físicas do Latossolo Vermelho submetido a diferentes tempos de adoção do sistema plantio direto e mata nativa.

\begin{tabular}{|c|c|c|c|c|}
\hline \multirow{2}{*}{$\begin{array}{l}\text { Camada } \\
\text { (m) }\end{array}$} & \multicolumn{4}{|c|}{ Sistema de uso e manejo do solo } \\
\hline & PD2 & PD4 & PD6 & $\mathrm{MN}$ \\
\hline & \multicolumn{4}{|c|}{ Macroporosidade $\left(\mathrm{m}^{3} \mathrm{~m}^{-3}\right)$} \\
\hline $0-0,10$ & $0,179 \mathrm{Ba}$ & $0,144 \mathrm{Ba}$ & $0,165 \mathrm{Ba}$ & $0,393 \mathrm{Aa}$ \\
\hline $0,10-0,20$ & $0,114 \mathrm{Bb}$ & $0,123 \mathrm{Ba}$ & $0,105 \mathrm{Ba}$ & $0,314 \mathrm{Ab}$ \\
\hline \multirow[t]{2}{*}{$0,20-0,30$} & $0,134 \mathrm{Bab}$ & $0,095 \mathrm{Ba}$ & $0,130 \mathrm{Ba}$ & $0,224 \mathrm{Ac}$ \\
\hline & \multicolumn{4}{|c|}{ Microporosidade $\left(\mathrm{m}^{3} \mathrm{~m}^{-3}\right)$} \\
\hline $0-0,10$ & $0,319 \mathrm{Cc}$ & $0,336 \mathrm{BCc}$ & $0,405 \mathrm{Ac}$ & $0,352 \mathrm{Bc}$ \\
\hline $0,10-0,20$ & $0,331 \mathrm{Cb}$ & $0,338 \mathrm{BCb}$ & $0,432 \mathrm{Ab}$ & $0,376 \mathrm{Bb}$ \\
\hline \multirow[t]{2}{*}{$0,20-0,30$} & $0,337 \mathrm{Ca}$ & $0,382 \mathrm{BCa}$ & $0,438 \mathrm{Aa}$ & $0,406 \mathrm{Ba}$ \\
\hline & \multicolumn{4}{|c|}{ Porosidade total $\left(\mathrm{m}^{3} \mathrm{~m}^{-3}\right)$} \\
\hline $0-0,10$ & $0,497 \mathrm{Ca}$ & $0,479 \mathrm{Ca}$ & $0,570 \mathrm{Ba}$ & $0,745 \mathrm{Aa}$ \\
\hline $0,10-0,20$ & $0,451 \mathrm{Ca}$ & $0,461 \mathrm{Ca}$ & $0,537 \mathrm{Ba}$ & $0,691 \mathrm{Ab}$ \\
\hline \multirow[t]{2}{*}{$0,20-0,30$} & $0,464 \mathrm{Ba}$ & $0,476 \mathrm{Ba}$ & $0,568 \mathrm{Aa}$ & $0,630 \mathrm{Ac}$ \\
\hline & \multicolumn{4}{|c|}{ Densidade do solo $\left(\mathrm{Mg} \mathrm{m}^{-3}\right)$} \\
\hline $0-0,10$ & $1,655 \mathrm{ABb}$ & $1,725 \mathrm{Aa}$ & $1,500 \mathrm{Bb}$ & $0,770 \mathrm{Cc}$ \\
\hline $0,10-0,20$ & $1,872 \mathrm{Aa}$ & $1,800 \mathrm{Aa}$ & $1,695 \mathrm{Aa}$ & $1,085 \mathrm{Bb}$ \\
\hline $0,20-0,30$ & $1,725 \mathrm{ABab}$ & $1,820 \mathrm{Aa}$ & $1,545 \mathrm{Bab}$ & $1,290 \mathrm{Ca}$ \\
\hline & \multicolumn{4}{|c|}{ Diâmetro médio ponderado dos agregados (mm) } \\
\hline $0-0,10$ & $3,86 \mathrm{Ca}$ & $3,40 \mathrm{Da}$ & $4,33 \mathrm{Ba}$ & $5,82 \mathrm{Aa}$ \\
\hline $0,10-0,20$ & $2,72 \mathrm{Cb}$ & $2,34 \mathrm{Db}$ & $3,47 \mathrm{Bb}$ & $5,86 \mathrm{Aa}$ \\
\hline $0,20-0,30$ & $2,79 \mathrm{Cb}$ & $1,82 \mathrm{Db}$ & $3,35 \mathrm{Bb}$ & $5,79 \mathrm{Aa}$ \\
\hline
\end{tabular}

MN: mata nativa; PD2: plantio direto com 2 anos de condução; PD4: plantio direto com 4 anos de condução; PD6: plantio direto com 6 anos de condução. Médias seguidas da mesma letra não diferem estatisticamente pelo teste de Tukey a 5\%. Letras maiúsculas comparam as médias na linha e minúsculas na coluna.

Na camada 0,20-0,30 m do PD4 e na camada 0,10-0,20m do PD6, a macroporosidade foi próxima a $0,10 \mathrm{~m}^{3} \mathrm{~m}^{-3}$, mínimo adequado para as trocas líquidas e gasosas entre o ambiente externo e o solo e considerado crítico para o crescimento das raízes da maioria das culturas (Taylor \& Ashcroft, 1972). Demonstrou que a degradação do solo pelo cultivo e tempo de adoção do sistema plantio direto ocorreu, principalmente, pela redução da macroporosidade, concordando com resultados observados por Argenton et al. (2005).

A densidade do solo na $\mathrm{MN}$ aumentou com a profundidade do solo, devido a maior quantidade de $\mathrm{MO}$ em sua superfície (Tabela 2). Para o PD2 e PD6, a densidade do solo foi menor na camada de $0-0,10 \mathrm{~m}$ em relação apenas à camada de 0,10-0,20 $\mathrm{m}$ que não apresentaram diferença para a camada de $0,20-0,30 \mathrm{~m}$, indicando uma maior compactação na camada de $0,10-0,20 \mathrm{~m}$ ou a ação dos mecanismos rompedores do solo utilizados para 
deposição do adubo e semente utilizados na semeadora/adubadora de plantio direto, que trabalham numa profundidade de aproximadamente $0,12 \mathrm{~m}$. Em todas as camadas, a densidade do solo foi inferior na $\mathrm{MN}$ com relação as áreas de plantio direto, o que segundo Oliveira et al. (2003), é resultado da interferência do homem por meio da ação de máquinas e equipamentos que alteraram a densidade do solo nos diferentes sistemas de plantio. Essa compactação, em comparação à condição original, foi devida às pressões exercidas sobre o solo pelo trânsito de máquinas e implementos agrícolas, conforme constatado também por Argenton et al. (2005) e Souza et al. (2005). Resultados semelhantes foram obtidos por Spera et al. (2004), que verificaram que a floresta subtropical apresentou a menor densidade do solo em relação aos sistemas de uso do solo estudados.

Nas camadas de 0-0,10 m e 0,20-0,30 m das áreas cultivadas, a densidade do solo foi maior para o PD4 em relação apenas ao PD6, e na camada de 0,10-0,20 m, não foi observada diferença para a densidade do solo. Segundo Souza et al. (2005), geralmente ocorre aumento da densidade do solo nos primeiros anos, em decorrência da acomodação e que, posteriormente, pode diminuir, em virtude do incremento de matéria orgânica no sistema de plantio direto.

Verifica-se, pela Tabela 2, que o diâmetro médio ponderado (DMP) em todas as camadas foi superior na $\mathrm{MN}$ do que nas áreas sob sistema plantio direto. Comparando a vegetação nativa de Cerrado com o uso do solo no sistema plantio direto em um Latossolo Vermelho-Escuro, Mendes et al. (2003) observaram maior estabilidade de agregados no Cerrado do que no PD. Concordando com Albuquerque et al. (2005), que demonstrou em seu trabalho que o manejo do solo provoca a oxidação da matéria orgânica, principalmente dos macroagregados com redução de sua estabilidade.

O DMP no PD2 e PD4 foi inferior ao do PD6 já que, segundo Spera et al. (2004), este solo permaneceu por um maior período coberto por material vegetal, ocorrendo intensa atividade biológica, resultando em maior formação e estabilização de agregados. Resultados obtidos por Araújo et al. (2004) mostram que modificações nos teores de MO do solo estão associadas a diferentes fatores, em especial à intensidade de revolvimento do solo, podendo ter reflexos na forma e estabilidade da estrutura, com conseqüências no comportamento físico do solo. Pôde-se verificar que seis anos de adoção do sistema plantio direto permitiu o aumento do DMP, concordando com Campos et al. (1995), que o sistema plantio direto nem sempre causa aumento na densidade do solo, podendo, inclusive, diminuí-la e aumentar a porosidade e o diâmetro dos agregados, com o passar do tempo de cultivo.

A MN não apresentou diferença para o DMP entre as camadas estudadas. Por outro lado, nos sistemas de plantio direto, houve maior estabilidade de agregados na camada de 0$0,10 \mathrm{~m}$, o que pode estar relacionado com a nula ou pequena movimentação do solo no sistema de plantio direto (Oliveira et al., 2003).

A MN apresentou a maior condutividade hidráulica devido a sua maior macroporosidade, porosidade total e menor densidade do solo (Figura 1). A condutividade hidráulica decresceu com o aumento da densidade do solo, concordando com os resultados obtidos por Stone et al. (2002). Não se observou diferença para condutividade hidráulica para os diferentes tempos de adoção do sistema plantio direto, mesmo com o PD6 apresentando menor densidade do solo nas camadas de $0-0,10 \mathrm{~m}$ e $0,20-0,30 \mathrm{~m}$ em relação ao PD4, e maior DMP em todas as camadas em relação ao PD2 e PD4, o que pôde ser justificado pelo volume de macroporos ser semelhante entre os sistemas de plantio direto (Tabela 2). Silva \& Katto (1997), trabalhando em Latossolo Vermelho Amarelo, constataram diferenças importantes na condutividade hidráulica saturada do solo sob plantio direto e sob manejo convencional, mostrando que pequenas diferenças na macroporosidade foram acompanhadas por elevadas 
diferenças de valores de condutividade hidráulica. A redução na macroporosidade tem grande efeito sobre a velocidade de infiltração de água e sobre o desenvolvimento radicular das plantas, por imprimir ao solo condições de baixa aeração, principalmente em solos argilosos (Cintra et al., 1983). Para Stone et al. (2002), o efeito da compactação na redução do tamanho dos poros que efetivamente transportam água, explica a redução da condutividade hidráulica com o aumento da densidade do solo, pois ela é altamente relacionada com raio médio ponderado para o fluxo reduzindo, de forma acentuada, o seu valor, com a redução do tamanho dos poros.

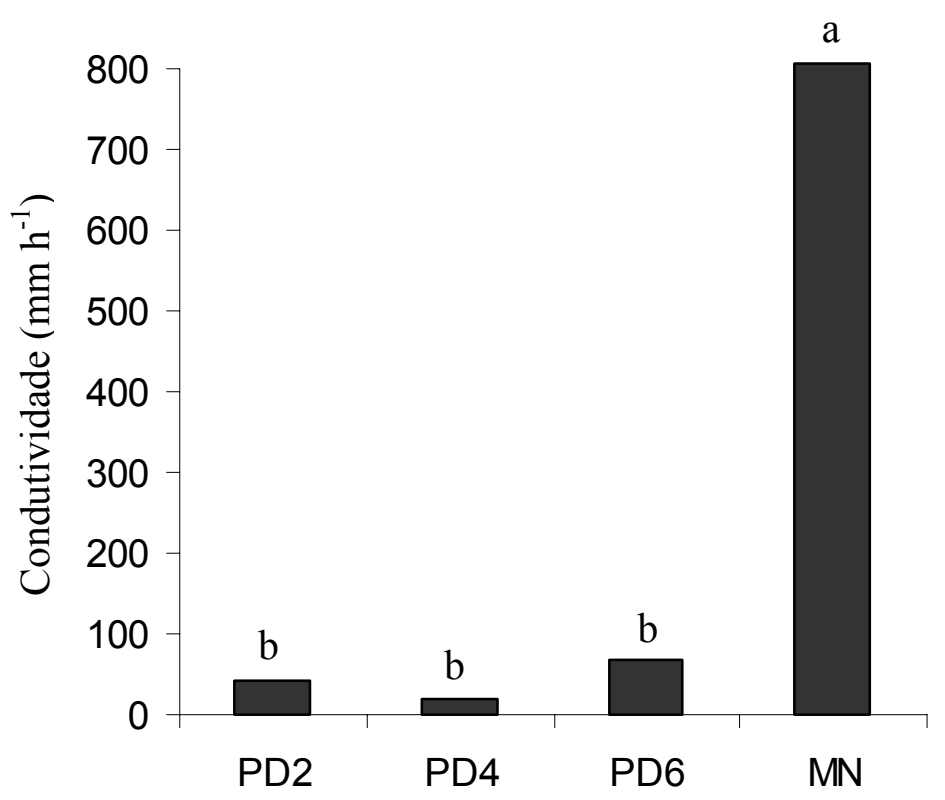

Figura 1. Condutividade hidráulica de um Latossolo Vermelho submetido a diferentes preparos e mata nativa. MN: mata nativa; PD2: plantio direto com 2 anos de condução; PD4: plantio direto com 4 anos de condução; PD6: plantio direto com 6 anos de condução. Médias seguidas da mesma letra não diferem estatisticamente pelo teste de Tukey a $5 \%$. $(\mathrm{CV}=53,53 \%)$

Na Figura 2, são apresentadas as curvas de retenção de água em diferentes camadas e tipos de uso e manejo do Latossolo Vermelho. Em tensões superiores a 0,006 $\mathrm{MPa}$, correspondente à capacidade de campo, em todas as camadas o PD6 apresentou maior retenção de água, seguido, respectivamente, da MN, PD4 e PD2. A maior ou menor retenção de água pelos diferentes tratamentos obedeceu ao volume de microporos apresentados por estes, ou seja, a maior retenção de água obtida pelo PD6 é devido à maior microporosidade observada neste tratamento em todas as camadas, e a menor retenção de água obtida pelo PD2 é devido a sua menor microporosidade (Tabela 2), concordando com Araújo et al. (2004), que também constataram que o aumento da densidade do solo resultou num aumento da água retida, o qual foi devido à alteração na distribuição do tamanho de poros, com o aumento de poros de menor diâmetro. De semelhante modo, Dexter (2004a) afirmou que o elevado teor de argila e o baixo conteúdo de matéria orgânica associados induzem à formação de poros de diâmetro reduzido, que mantêm a água retida mesmo em tensões elevadas, dificultando a absorção pelas plantas. 

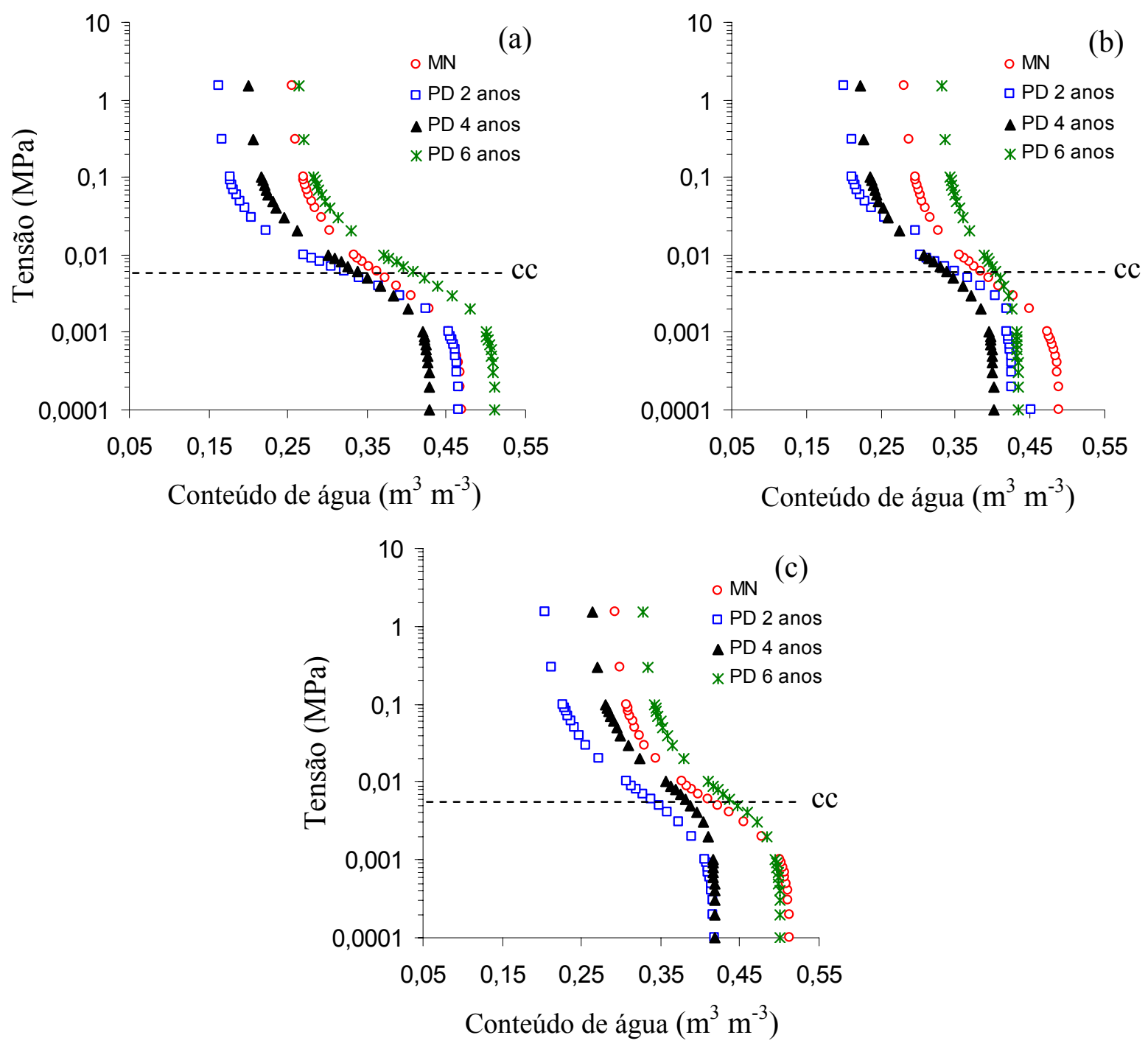

Figura 2. Curvas de retenção de água de um Latossolo Vermelho submetido a diferentes usos e manejos nas camadas de 0-0,10 m (a); 0,10-0,20 m (b) e 0,20-0,30 m (c). cc é tensão de $0,006 \mathrm{MPa}$ correspondente à capacidade de campo.

$\mathrm{Na}$ Figura 3, está apresentado o Índice S, que é um parâmetro que tem grande sensibilidade para distinguir alterações introduzidas pelo manejo na qualidade física do solo para o crescimento de plantas, obtido a partir do valor da inclinação da tangente no ponto de inflexão da curva de retenção de água (Dexter, 2004). A MN nas três camadas estudadas apresentou maior índice S com relação a todos os demais tratamentos (Figura 3), uma vez que possui ausência de tráfego de máquinas, ao contrário dos sistemas cultivados, indicando uma melhor configuração de poros do solo e, portanto, menor restrição física para o crescimento de raízes de plantas quer seja por aeração, restrição mecânica ou por características de 
retenção de água, conforme constatado por Dexter (2004). De acordo com os resultados, pode-se afirmar que o solo da $\mathrm{MN}$ possui uma qualidade estrutural superior ao solo dos sistemas cultivados, já que estes apresentam área trafegada por máquinas agrícolas, possuindo uma maior densidade do solo em função da compactação e, conseqüentemente, uma estrutura física degradada (Dexter, 2004). Observou-se também que houve uma diminuição do Índice S em profundidade, demonstrando que a camada de 0-0,10 $\mathrm{m}$ apresentou melhores condições físicas para o crescimento radicular em todos os tratamentos, com exceção apenas para o PD4, no qual a camada de $0-0,10$ m não apresentou diferença significativa para camada de 0,10 $0,20 \mathrm{~m}$.

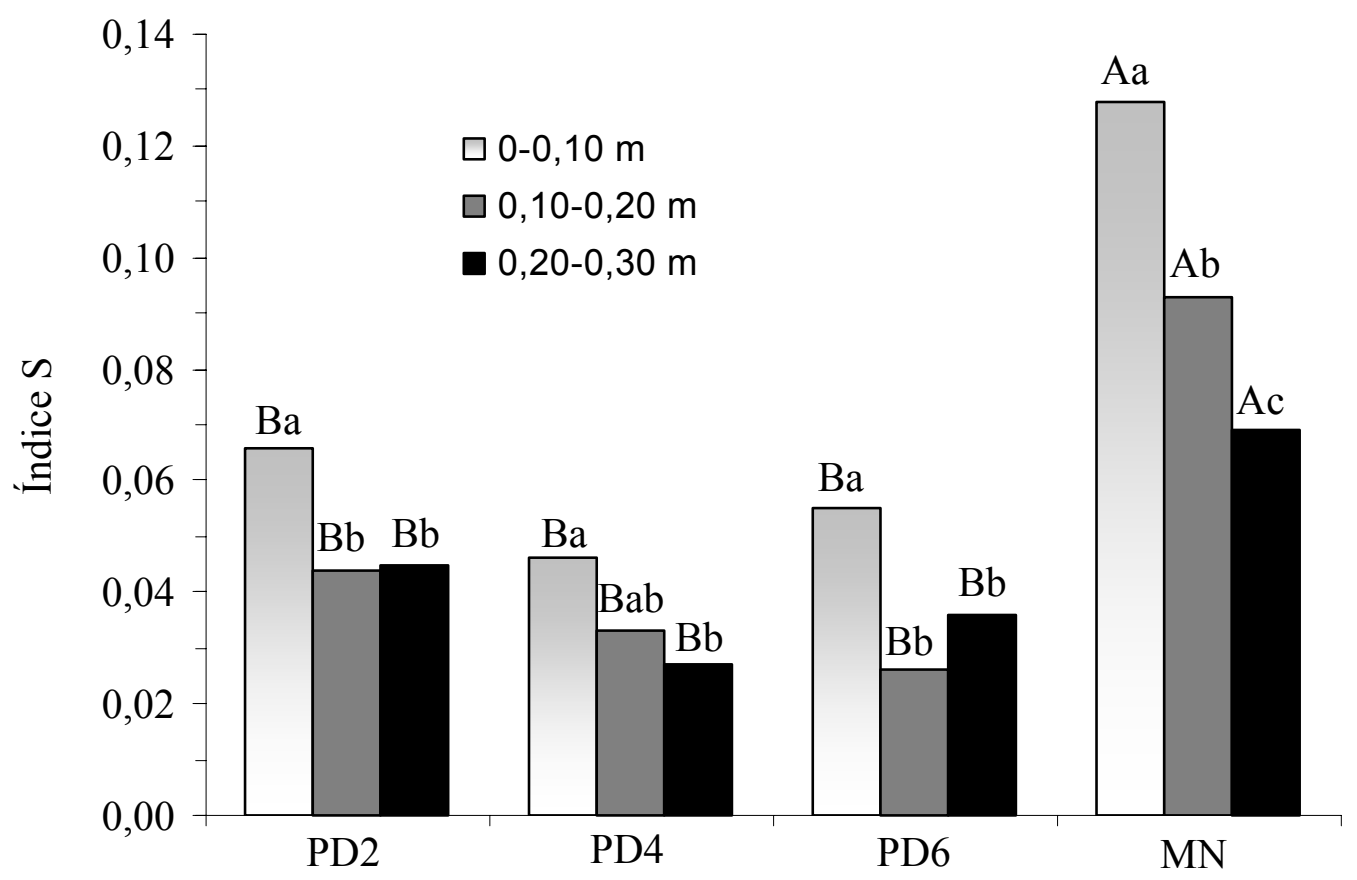

Figura 3. Índice $\mathrm{S}$ de um Latossolo Vermelho sob condições de mata nativa (MN), plantio direto com 2 anos (PD2), plantio direto com 4 anos (PD4) e plantio direto com 6 anos (PD6). Médias seguidas da mesma letra não diferem estatisticamente pelo teste de Tukey a 5\%. Letras maiúsculas referem-se à comparação entre tratamentos numa mesma camada e as minúsculas comparam médias de camadas de um mesmo tratamento. $(\mathrm{CV}=16,67 \%)$

As camadas $0,20-0,30 \mathrm{~m}$ do PD4 e 0,10-0,20 m do PD4 e PD6 apresentaram valores de $\mathrm{S}$ iguais a $0,027,0,025$ e 0,033 , respectivamente, podendo-se afirmar que possuem uma estrutura física degradada, uma vez que apresentaram valores de $\mathrm{S}$ inferiores a 0,035 , concordando com Dexter (2004). Nessas camadas, foi observada macroporosidade próxima a $0,10 \mathrm{~m}^{3} \mathrm{~m}^{-3}$ (Tabela 2), que segundo Taylor \& Ashcroft (1972), é o mínimo adequado para as trocas líquidas e gasosas dentre o ambiente externo e o solo considerado crítico para o crescimento das raízes da maioria das culturas.

Segundo Dexter (2004), a redução do S nas áreas cultivadas pode estar associada a uma diminuição do pico da distribuição de freqüência de poros, resultando em um "achatamento" vertical da curva de retenção de água, pela redução dos poros estruturais. Isso demonstra que a perda da qualidade física pelo cultivo ocorreu, principalmente, pela redução da macroporosidade, concordando com resultados observados por Argenton et al. (2005). 


\section{CONCLUSÕES}

1. A área de mata nativa; apresentou maior teor de matéria orgânica em relação às áreas de plantio direto, sendo que 6 anos de adoção deste sistema não foram suficientes para alterar o teor de matéria orgânica do solo.

2. A maior porosidade total e diâmetro médio ponderado dos agregados foram observados na área de mata nativa, entretanto, a adoção por seis anos do sistema plantio direto foram suficientes para melhorar estas propriedades físicas do solo.

2. A área de mata nativa apresentou melhor qualidade física do solo, determinada pelo índice S, condutividade hidráulica, macroporosidade e teor de matéria orgânica, em relação às áreas de plantio direto, sendo que seis anos de adoção deste sistema não foram suficientes para melhorar sua qualidade física.

\section{REFERÊNCIAS BIBLIOGRÁFICAS}

ALBUQUERQUE, J. A.; SANGOI, L.; ENDER, M. Efeitos da integração lavoura-pecuária nas propriedades físicas do solo e características da cultura do milho. Revista Brasileira de Ciência do Solo, Viçosa, v.25, n.3, p.717-723, 2001.

ALBUQUERQUE, J. A.; ARGENTON, J.; BAYER, C. Relação de atributos do solo com a agregação de um Latossolo Vermelho sob sistemas de preparo e plantas de verão para cobertura do solo. Revista Brasileira de Ciência do Solo, Viçosa, v.29, n.3, p.415-424, 2005.

ARAÚJO; M. A.; TORMENA, C. A.; INOUE, T. T. Costa Efeitos da escarificação na qualidade física de um latossolo vermelho distroférrico após treze anos de semeadura direta. Revista Brasileira de Ciência do Solo, Viçosa, v.28, n.3, p. 495-504, 2004.

ARGENTON, J.; ALBUQUERQUE, J. A.; BAYER, C. Comportamento de atributos relacionados com a forma da estrutura de Latossolo Vermelho sob sistemas de preparo e plantas de cobertura. Revista Brasileira de Ciência do Solo, Viçosa, v.29, n.3, p.425-435, 2005.

BEUTLER, A. N. ; CENTURION, J. F. Efeito do conteúdo de água e da compactação do solo na produção de soja. Pesquisa Agropecuária Brasileira, Brasília, v.38, n.7, p.849-856, 2003.

BEUTLER, A. N.; CENTURION, J. F. Compactação do solo no desenvolvimento radicular e na produtividade da soja. Pesquisa Agropecuária Brasileira, Brasília, v.39, n.6, p.581-588, 2004.

BLAKE, G. R.; HARTGE, K. H. Particle density. In: KLUTE, A. Methods of soil analysis: physical and mineralogical methods. Madison: American Society of Agronomy, 1986. p.377382.

CAMPOS, B. C.; REINERT, D.J.; NICOLODI, R.; RUEDELL, J.; PETRERE, C. Estabilidade estrutural de um Latossolo Vermelho-Escuro distrófico após sete anos de rotação 
de culturas e sistemas de manejo de solo. Revista Brasileira de Ciência do Solo, Viçosa, v.19, n.1, p.121-126, 1995.

CARVALHO, M. A. C.; ATHAYDE, M. L. F. Adubação verde e sistemas de manejo do solo na produtividade do algodoeiro. Pesquisa Agropecuária Brasileira, Brasília, v.39, n.12, p.1205-1211, 2004.

CINTRA, F. L. D.; MIELNICZUK, J.; SCOPEL, I. Caracterização do impedimento mecânico em um Latossolo Roxo do Rio Grande do Sul. Revista Brasileira de Ciência do Solo, Viçosa, v.7, n.3, p.323-327, 1983.

CRUZ, A. C. R.; PAULETTO, E. A.; FLORES, C. A. Atributos físicos e carbono orgânico de um Argissolo Vermelho sob sistemas de manejo. Revista Brasileira de Ciência do Solo, Viçosa, v.27, n.6, p.1105-1112, 2003.

D'ANDREA, A. F.; SILVA, M. L. N.; CURI, N. Estoque de carbono e nitrogênio e formas de nitrogênio mineral em um solo submetido a diferentes sistemas de manejo. Pesquisa Agropecuária Brasileira, Brasília, v.39, n.2, p.179-186, 2004.

DANIELSON, R. E.; SUTHERLAND, P. L. Porosity. In: KLUTE, A. Methods of soil analysis. Madison: American Society of Agronomy, 1986. p.443-461.

DEXTER, A. R. Soil physical quality: Part I. Theory, effects of soil texture, density and organic matter, and effects on root growth. Geoderma, Amsterdam, v.120, n.3/4, 201-214, 2004.

ESCOSTEGUY, P. A. V.; HENKIN, D.; CALDEIRA, M. H. Resíduos culturais e resultado da análise de solo coletado com diferentes amostradores no sistema de plantio direto. Ciência Rural, Santa Maria, v.35, n.1, p.69-75, 2005.

FREITAS, P. L.; BLANCANEAUX, P.; GAVINELLI, E. Nível e natureza do estoque orgânico de latossolos sob diferentes sistemas de uso e manejo. Pesquisa Agropecuária Brasileira, Brasília, v.35, n. 1, p.157-170, 2000.

GEE, G. W.; BAUDER, J. W. Particle-size analysis. In: KLUTE, A. Methods of soil analysis: Part 1 -Physical and mineralogical methods. Madison: American Society of Agronomy, 1986. p. 383-409.

GENUCHTEN, M. T. A. A. closed-form equation for predicting the hydraulic conductivity of unsaturated soils. Soil Science Society of America Journal, Madison, v.44, n.5, p.892-897, 1980.

KIEHL, E. J. Manual de edafologia. São Paulo: Ceres, 1979. 262 p.

KLEIN, V. A.; LIBARDI, P. L. Densidade e distribuição do diâmetro dos poros de um Latossolo Vermelho, sob diferentes sistemas de uso e manejo. Revista Brasileira de Ciência do solo, Viçosa, v.26, n.4, p.857-867, 2002. 
KLUTE, A. Water retention: laboratory methods. In: KLUTE, A. Methods of soil analysis. Madison: American Society of Agronomy, 1986, p.635-662.

LOVATO, T.; MIELNICZUK, J.; BAYER, C. Adição de carbono e nitrogênio e sua relação com os estoques no solo e com o rendimento do milho em sistemas de manejo. Revista Brasileira de Ciência do Solo, Viçosa, v. 28, n.1, p.175-187, 2004.

MENDES, I. C.; SOUZA, L. V.; RESCK, D. V. S. Propriedades biológicas em agregados de um Latossolo Vermelho-Escuro sob plantio convencional e direto no Cerrado. Revista Brasileira de Ciência do Solo, Viçosa, v.27, n.3, p.435-443, 2003.

OLIVEIRA, G. C.; DIAS JUNIOR, M. S.; RESCK, D. V. S. Alterações estruturais e comportamento compressivo de um Latossolo Vermelho distrófico argiloso sob diferentes sistemas de uso e manejo. Pesquisa agropecuária brasileira, Brasília, v.38, n.2, p.291-299, 2003.

RAIJ, B. V.; QUAGGIO, J. A.; CANTARELlA, H.; FERREIRA, M.; LOPES, A. S.; BATAGLIA, O. C. Análise química do solo para fins de fertilidade. Campinas: Fundação Cargill. 1987. 170p.

SILVA, C.L.; KATO, E. Efeitos do selamento superficial na condutividade hidráulica saturada da superfície de um solo sob cerrado. Pesquisa Agropecuária Brasileira, Brasília, v.32, n.2, p.213-220, 1997.

SPERA, S. T.; SANTOS, H. P.; FONTANELI R. S.; TOMM, G. O. Efeitos de sistemas de produção de grãos envolvendo pastagens sob plantio direto nos atributos físicos de solo e na produtividade. Revista Brasileira de Ciência do Solo, Viçosa, v.28, n.3, p.533-542, 2004.

SOUZA, E. D.; CARNEIRO, M. A. C.; PAULINO, H. B. Atributos físicos de um Neossolo Quartzarênico e um Latossolo Vermelho sob diferentes sistemas de manejo. Pesquisa Agropecuária Brasileira, Brasília, v.40, n.11, p.1135-1139, 2005.

STONE, L. F.; GUIMARAES, C. M.; MOREIRA, J. A. A. Compactação do solo na cultura do feijoeiro. I: efeitos nas propriedades físico-hídricas do solo. Revista Brasileira de Engenharia Agrícola e Ambiental, Campina Grande, v.6, n.2, p.207-212, 2002.

TAYLOR, S. A.; ASHCROFT, G. L. Physical edaphology - the physics of irrigated and non irrigated soils. San Francisco, W.H. Freeman, 1972. 532p.

TOGNON, A. A.; DEMATTE, J. L. I.; DEMATTE, J. A. M. Teor e distribuição da matéria orgânica em latossolos das regiões da floresta amazônica e dos cerrados do Brasil central. Scientia Agricola, Piracicaba, v.55, n.3, p.343-354, 1998.

TORMENA, C. A.; FRIEDRICH, R.; PINTRO, J. C. Propriedades físicas e taxa de estratificação de carbono orgânico num Latossolo Vermelho após dez anos sob dois sistemas de manejo. Revista Brasileira de Ciência do Solo, Viçosa, v. 28, n.6, p.1023-1031, 2004. 
YOODER, R. E. A direct method of agregate analyses sois and a study of the physical nature of erosin losses. Journal of America Society Agronomy, Madison, v.28, n.1, p.337-351, 1936. 